\title{
Impact Safety Control Strategy for the Battery System of an Example Electric Bus
}

\author{
Zhen-po Wang, Jia Liu, Hai-tao Li, and Lei Zhang \\ Beijing Institute of Technology, Beijing 100081, China \\ Correspondence should be addressed to Zhen-po Wang; wangzhenpo@bit.edu.cn
}

Received 1 December 2014; Revised 2 February 2015; Accepted 3 March 2015

Academic Editor: Łukasz Jankowski

Copyright (C) 2015 Zhen-po Wang et al. This is an open access article distributed under the Creative Commons Attribution License, which permits unrestricted use, distribution, and reproduction in any medium, provided the original work is properly cited.

\begin{abstract}
This paper proposes a side impact safety control strategy for the battery system, aiming at defusing the hazards of unacceptable behaviors of the battery system such as high-voltage hazards. Based on some collision identification metrics, a side impact discrimination algorithm and a side impact severity algorithm are developed for electric buses. Based on the study on the time to break for power battery, the side impact discrimination algorithm response time is about $20 \mathrm{~ms}$ posing a great challenge to the side impact discrimination algorithm. At the same time, the reliability of the impact safety control strategy developed in this paper is evaluated for other plausible side impact signals generated by finite element analysis. The results verify that the impact safety control strategy exhibits robust performance and is able to trigger a breaking signal for power battery system promptly and accurately.
\end{abstract}

\section{Introduction}

In order to address serious concerns over energy sustainability and environmental pollution issues, governments, automotive industry, and academia are endeavoring to expedite a paradigm shift to a green transportation. Electric vehicles have been widely accepted as an integral part of such a high-efficiency system, attributing to the use of electricity that can potentially diversify the power sources of vehicles, thus reducing the excessive reliance on fossil fuels while facilitating the adoption of renewable energy [1-3]. The battery system plays an important role in fulfilling the requirements of driving performance, as well as ensuring operation safety. However, the safety issues related to a given battery technology pose a significant challenge to ensuring the overall safety performance, especially in severe road accidents such as side impacts. It is estimated that side impacts at road intersections claim a portion of $30 \%-40 \%$ in vehicle-to-vehicle accidents across the world [4]. However, side impacts are usually hard to evade since the response time for the drivers to take necessary actions is too short, even though it may be possible to perceive the imminent risks. Worse more, side impacts are always fatal because of the limited deformation space $[5,6]$ to absorb impact energy. This precondition, combined with high intrusion velocities, results in a short time between the beginning of the collision and the moment when the intruding door panel contacts the power battery. In such cases, short-circuit phenomenon [7] may occur within the battery system, which can easily evolve into more serious incidents such as thermal runaway and even flaming and explosion, owing to the use of volatile materials such as lithium metal and flammable solvents [8]. When working beyond the stability range of the system (in terms of temperature and voltage), a series of undesirable reactions may occur within the battery system such as electrolyte reduction [9], subsequently incurring thermal runaway [10-13] that entails significant threats such as explosion phenomenon. Generally, safety of the battery system needs to be addressed at the cell, module, pack, and ultimately vehicle levels.

In addition, high-voltage power battery pack is often leveraged to lower the power loss in electric vehicles, where the rated voltage is up to between $200 \mathrm{~V}$ and $500 \mathrm{~V}$ [14]. Consequently, there is a high possibility that electrical harm would be incurred to the passengers when the high-voltage system is electrically mounted to the vehicle body under side impacts [15-18]. However, there is an explicit absence of reported studies pertaining active security control for 


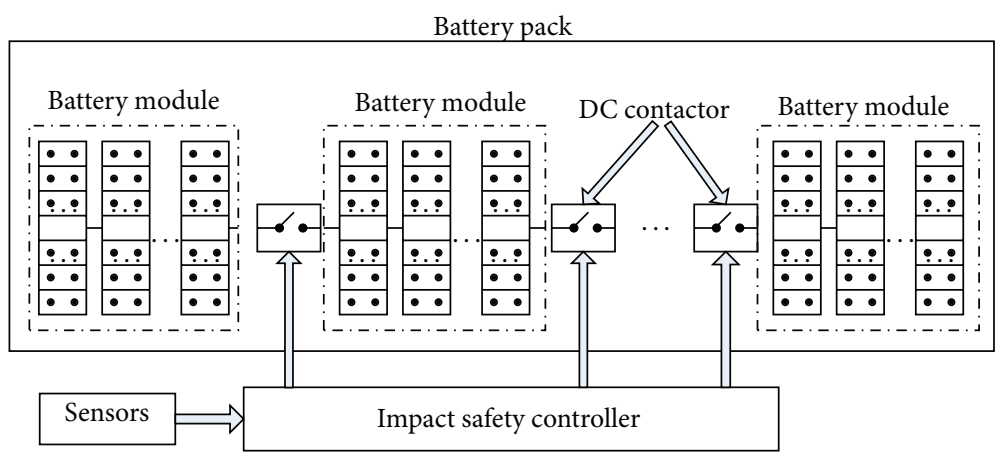

FIGURE 1: Active security control system for battery pack.

the battery system after collision accidents in the literature. To bridge the gap, it is meaningful to carry relevant research on safety for power battery system under side impacts.

In this paper, a side impact safety control strategy is presented in an example electric bus, aiming at defusing the hazards of unacceptable behaviors of the battery system such as high-voltage hazards. A side impact discrimination algorithm is proposed to detect the side impact by considering multimetrics, that is, velocity change and integral for absolute acceleration. Once a side impact is confirmed, a severity algorithm is employed to assess the extent of the accident, which classifies the accident into three levels. In serious impacts, the side impact safety control strategy can realize the electrical segregation of different modules within the battery pack by making the DC contractors breaking their electric loops, which are duly placed between adjacent modules. This can significantly reduce the voltage level of the battery pack, thus effectively suppressing the hazards on account of the possible terminal exposure to the passengers. In order to verify the effectiveness of the proposed method, the finite element models of an example electric bus and a moving deformable barrier are established in Hyperworks to simulate the real side impact accidents. The results show that the control strategy can generate the breaking signal for power battery pack both promptly and accurately.

\section{Breaking Strategy and Side Impact Recognition Algorithm for Power Battery System}

2.1. Breaking Strategy for Power Battery System. In order to ensure the safety of power pack during road accidents, an active safety control system is proposed as shown in Figure 1. It consists of impact detection sensors, an impact safety controller, and DC contactors. The DC contactors are deployed to make the high-voltage battery pack break into a number of low-voltage battery modules. The whole battery pack electrically decomposes into $n(n \geq 2)$ battery modules, making sure that open-circuit voltage of each module drops to less than $36 \mathrm{~V}$ that is widely adopted as a threshold voltage for safety concerns. As a result, the possible hazards to the passengers can be effectually defused in serious road collisions.
To avoid possible malfunctions (e.g., incapability of braking and steering) in serious impacts, a breaking scheme for power battery system is also put forward. The detailed schematic is shown in Figure 2. If one of battery packs detects a collision signal ( $n$ represents the battery pack), the controller functions to trigger a breaking signal to execute the corresponding DC contactor $n$, resulting in breaking tis electrical loop. Then the DC contactor $n n$ is closed. Subsequently the battery pack $n$ is shorted, and the closed-loop consists of other battery packs and drive motor once again. In this way, electric buses can still have the ability of braking or steering even in serious impacts due to the closed-loop for the power battery system. To ensure that contactor $n$ and $n n$ cannot be closed simultaneously, a controllable SPDT switch is placed between them.

2.2. Common Collision Identification Metrics. To realize the accurate and prompt detection of side impacts as well as to evaluate impact severity, several metrics have been proposed, which are shown as follows [19-25]:

(1) acceleration, $a(t)$;

(2) velocity change, $\Delta V=\int a(t) d t$;

(3) integral for absolute acceleration, $\int|a(t)| d t$;

(4) jerk, $j(t)=d a(t) / d t$;

(5) power, $p(t)=d E(t) / d t=m v(t) a(t)$;

(6) specify power, $d p(t) / d t=m v(t) j(t)+m a^{2}(t)$.

The preprocess of denoising for acquired acceleration signal $a(t)$ is done.

These metrics can be generally grouped into three categories, that is, impact force-dependent metrics, impact energy-dependent metrics, and combination metrics. Since the acceleration is proportional to the impact force, the acceleration and the jerk can be regarded as impact forcedependent variables to gauge the collision strength. The acceleration change is the difference between two consecutive acceleration values sampled at a fixed rate. In addition, since the kinetic energy of the vehicle is transformed to the elastic-plastic energy through elastic-plastic deformation of the vehicle structure during impacts, the velocity change can be reasonably selected as another impact energy-dependent 


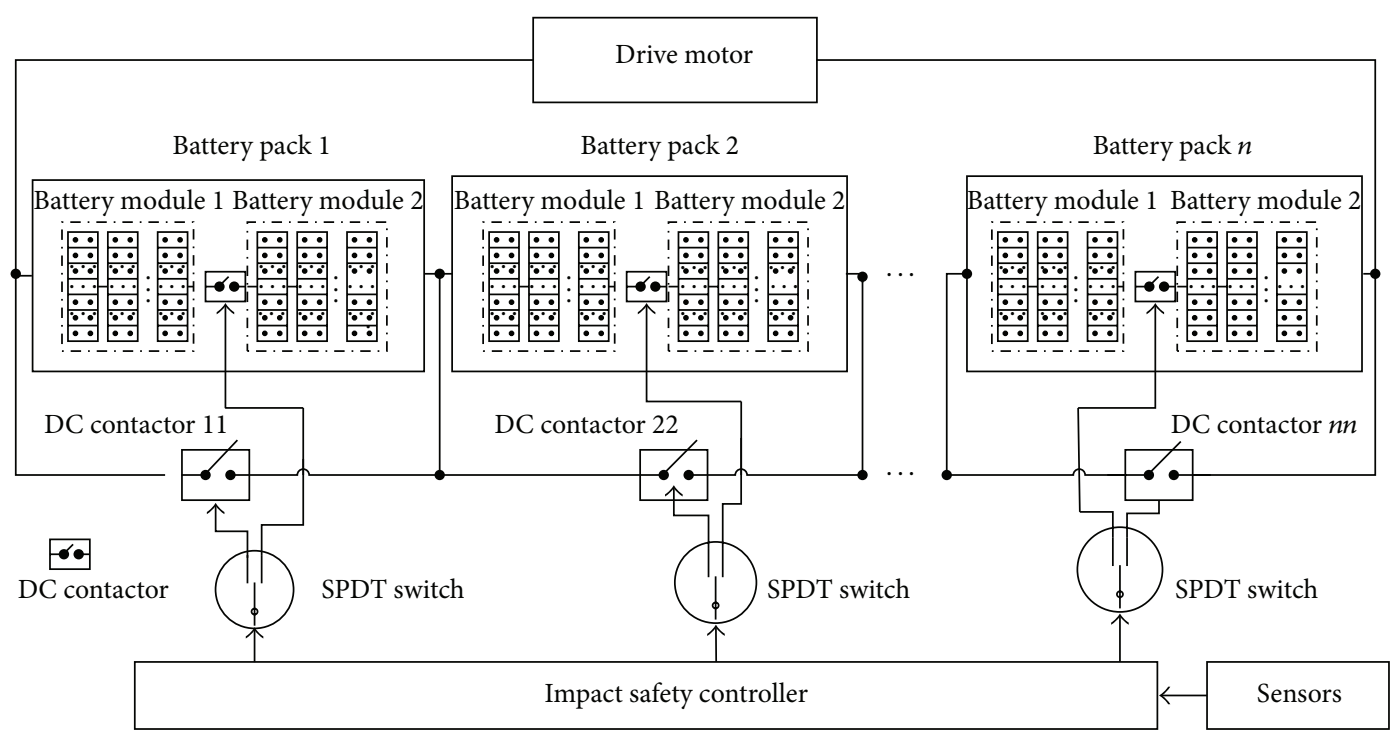

FIGURE 2: Breaking scheme of power battery system.

variable. Power and specify power are combination-type metrics of impact force-dependent metrics, representing in the collision strength and the collision energy absorbed.

2.3. Key Techniques for Simulation Model. FEM (finite element model) is an effective tool for simulation analysis. Based on FEM, the acceleration signal is recorded during impact simulations. In addition to the accuracy of finite element computing method, the precision of impact simulation is also highly dependent on the fidelity of the simulation model. The main factors influencing the simulation accuracy can be attributed to three facets: model accuracy of moving deformable barrier (MDB), model accuracy of vehicle model, and battery pack model. For MDB, material invalidation and bonding technology with invalidation mode beam element are taken into consideration. Besides, solder type, material molding process, and material strain rate are also taken into account.

Finite element simulations have been conducted routinely in the past decade to evaluate and improve impact and safety designs for specific high-speed impact conditions. Knowledge of key modeling techniques had been accumulated for establishing an effective finite element model. These modeling techniques are summarized as follows.

(1) In order to obtain a smoother curve, the acceleration obtained by simulation should be filtered. Routinely, a frequency band of $300-400 \mathrm{~Hz}$ is always picked as the threshold [26].

(2) Material strain rate is a significant input parameter, which is closely related to the structure deformation, energy transfer, and absorption. So it is necessary to obtain dynamic stress-strain curve through a series of experiments.

(3) A full vehicle impact analysis involves interaction between all free surfaces, which includes contacts at
TABLE 1: Vehicle technical parameters.

\begin{tabular}{lc}
\hline Item & Parameters \\
\hline Length $\times$ Hig $\times$ Widt $/ \mathrm{mm}$ & $11850 \times 2540 \times 3300$ \\
axle base $/ \mathrm{mm}$ & 5800 \\
wheel base $($ front $/$ latter $) / \mathrm{mm}$ & $2096 / 1836$ \\
mass $/ \mathrm{kg}$ & 18000 \\
Battery & Lithium-ion battery \\
outer box & $798 \times 850 \times 375$ \\
Inner box & $810 \times 766 \times 310$ \\
\hline
\end{tabular}

all significant corners and edges. To this end, it is still strongly recommended that the segment-based contact search parameter should be considered when defining the contacts.

(4) The friction coefficient between the vehicle and MDB is set as 0.2 .

2.4. Finite Element Model of Electric Buses. The electric bus, BK612EV, was served as the simulation target in this study. The specifications [27] are shown in Table 1 . As to the battery pack, it consists of an outer box and an inner box with arrays of battery cells inside. The outer box is mounted on a door frame while the inner box is mechanically tied to the outer box. Since the vehicle's skeleton comprises a number of thin-walled square tubes, shell element is employed in the finite-element model. Due to the local instability of the straight beam under axial collisions, the straight beam will be collapsed. The thin wall of straight beams will wrinkle along some arc curve (radius $r$ ) [28,29], and the average of radius $r$ approximately is

$$
r=0.72 b^{1 / 3} \theta^{2 / 3},
$$

where $b$ is the cross sectional width; $\theta$ is the thickness. 


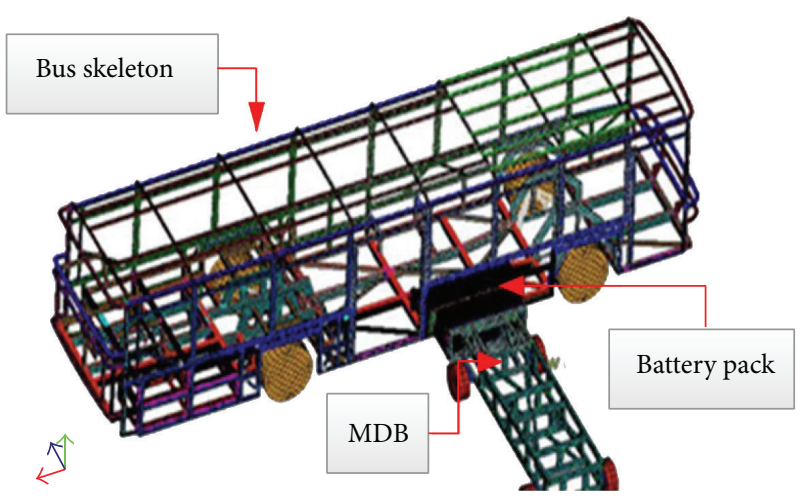

FIGURE 3: Electric buses finite element model.

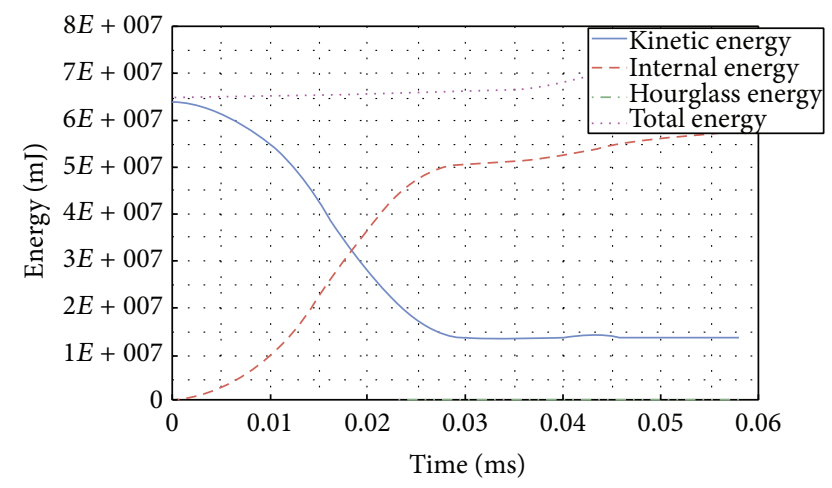

FIGURE 4: Energy variation.

In order to precisely depict the structure deformation in the collision, element size should be set less than half of the length of the arc. According to the equation $l=0.5 \pi r, 10 \mathrm{~mm}$, $50 \mathrm{~mm}$, and $20 \mathrm{~mm}$ are selected as the element sizes for the collision zone the no-collision zone and the go-between area, respectively.

According to the technical specification of BK612EV, Q235 and 16Mn are selected as vehicle skeleton material and chassis material, respectively. Then, the door frame material of the battery pack is Q235, and MAT24 is selected as piecewise linear plastic material model; the shell material of the battery is SMC, MAT1 is selected as elastic model; battery cathode and negative material are aluminum foil and copper foil, respectively, which are prone to plastic deformation in the collision, so MAT18 is selected as cell model; the vehicle model is shown in Figure 3.

Figure 4 depicts the curve of energy variation during the side impact. It is evident that the maximum kinetic energy sees a dramatical decline to a stable level during the course of side impact, while the internal energy evolves in the opposite trend, with $76.3 \%$ of the kinetic energy converted to the internal energy. The hourglass energy remains about $1 \%$ of the total impact energy, not more than $5 \%$. It is obvious that the energy variation is consistent with energy conservation law, thus verifying the reliability of the analysis results.

Impact speed is set as $35 \mathrm{~km} / \mathrm{h}$. Figure 5 shows the displacement contours of the vehicle at $20 \mathrm{~ms}$. Figure 6 shows

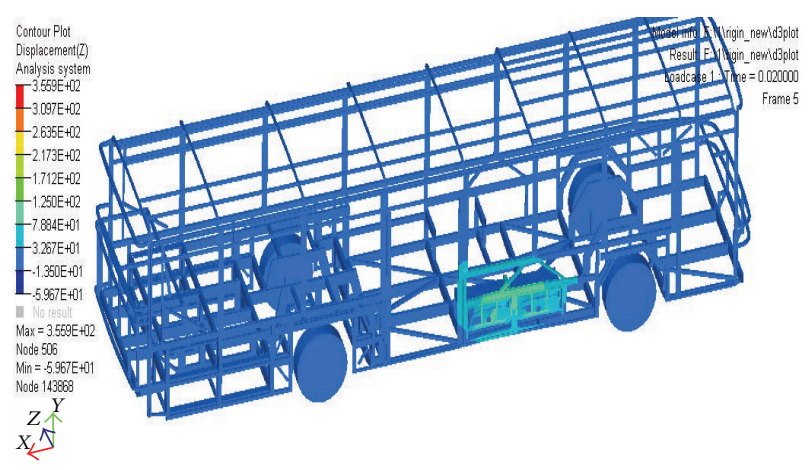

Figure 5: Displacement contours at $20 \mathrm{~ms}$.

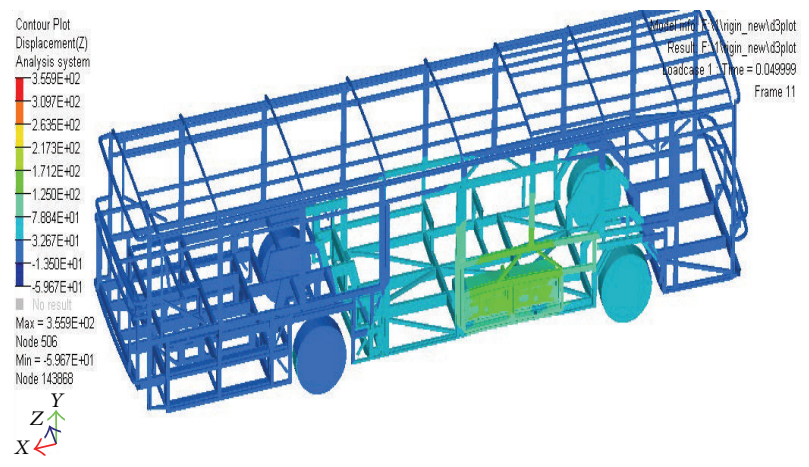

Figure 6: Displacement contours at $50 \mathrm{~ms}$.

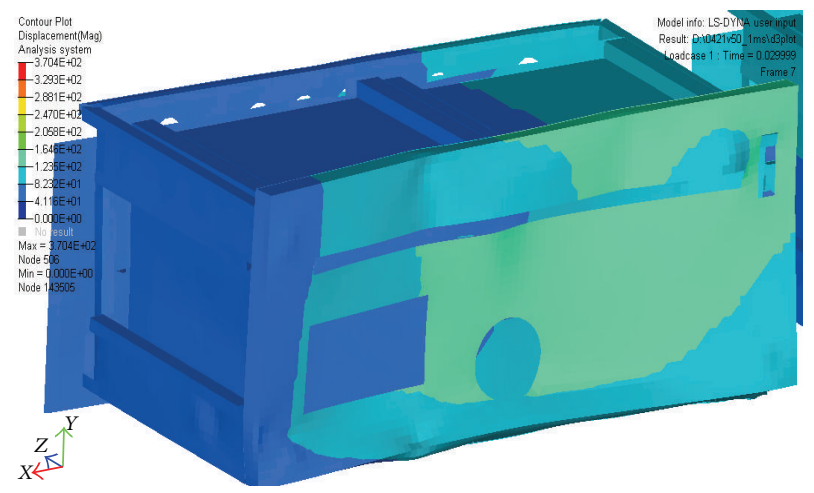

Figure 7: Displacement contours at $30 \mathrm{~ms}$.

the displacement contours of the vehicle at $50 \mathrm{~ms}$. The impact configuration is $100 \%$ side collision, and the installation site of battery pack is selected as the collision zone. So the deformation of the door frame and battery panel is great. Gradually, the kinetic energy is converted to the internal energy spreading to the other end of the bus skeleton.

Figures 7 and 8 show the displacement contours of the battery pack at $30 \mathrm{~ms}$ and $60 \mathrm{~ms}$, respectively. Part of the kinetic energy is absorbed by the battery panel and the rest is transferred to the bus skeleton by beams.

2.5. Characteristics for Side Impact Acceleration of Electric Bus. Figure 9 shows a curve of acceleration against different 


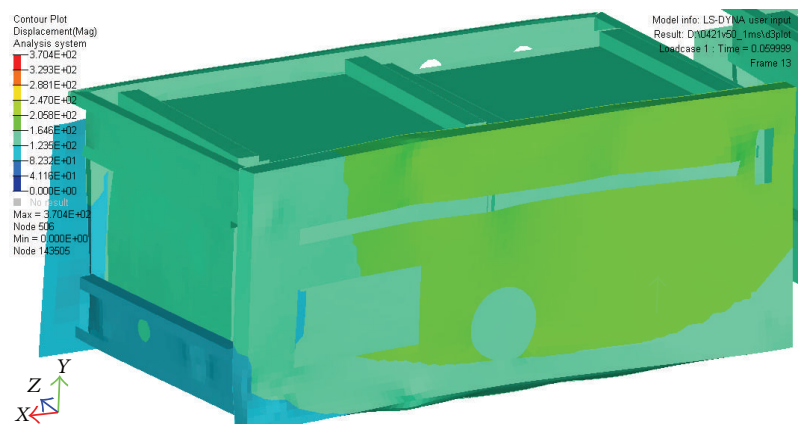

Figure 8: Displacement contours at $60 \mathrm{~ms}$.

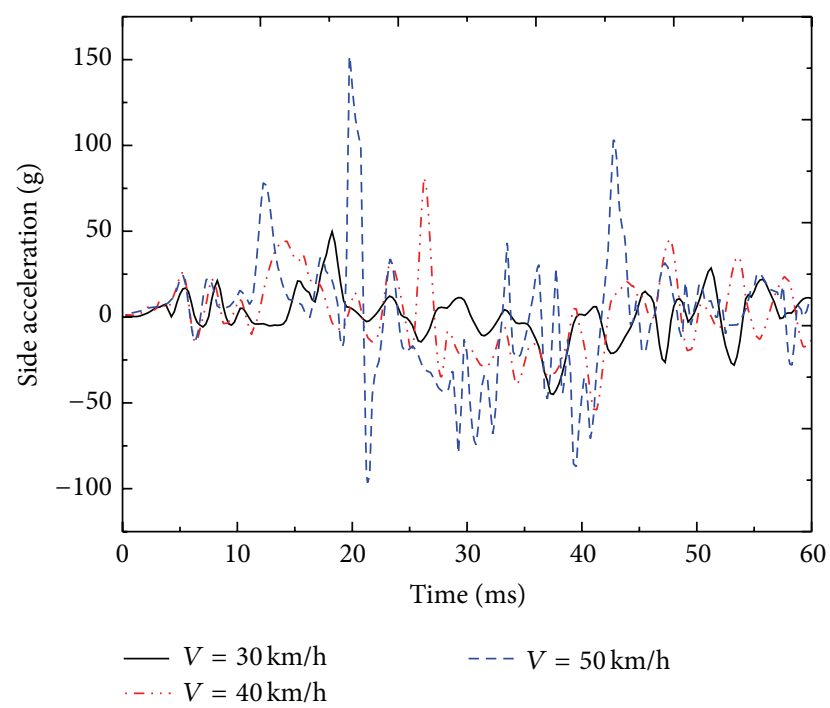

Figure 9: Acceleration curve against different impact velocity.

impact velocity obtained by finite element analysis (FEA). Although the acceleration curves are different, but they share the same characteristics: the acceleration curve fluctuates violently at the begin of side collision, and then the fluctuation amplitude decreases gradually while the fluctuation frequency increases slowly; the time to reach the peak acceleration moment arrives earlier due to increasing magnitude of collision speed.

2.6. Requirements for Breaking Algorithm. $T_{3}$ represents the latest time-to-break, as shown in Figure 10. According to the principle of identifying a collision signals early, $\Delta T_{1}$ $\left(\Delta T_{1}\right.$ represents the response time of collision identification algorithm) should be shorter in favor of reducing highvoltage electrical injury. Therefore, the response time of identification algorithm $\Delta T_{1}$ should satisfy the following formula:

$$
\Delta T_{1}<T_{3}-\Delta T_{2}
$$

where $\Delta T_{2}\left(\Delta T_{2}\right.$ represents the response time of a DC contactor) is a fixed-value for some DC contactor selected. The shorter the response time of DC contactor becomes, the longer the response time of identification algorithm becomes,

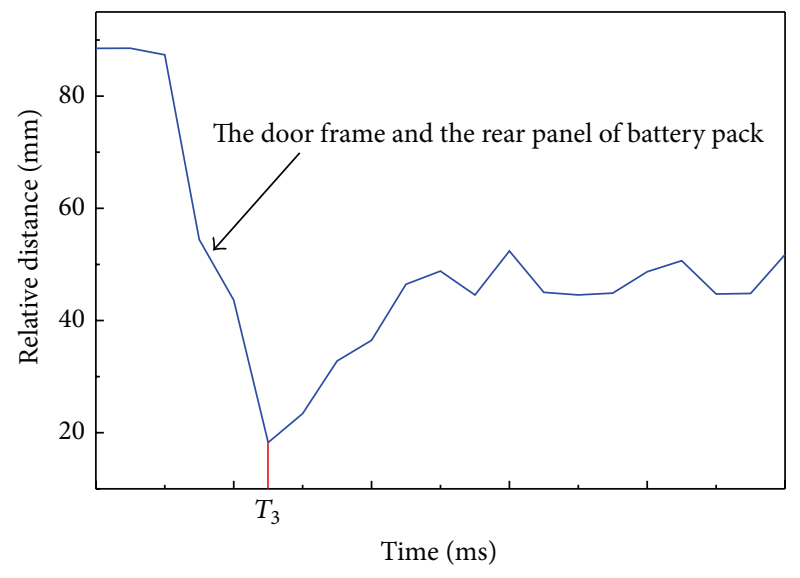

FIgURE 10: Schematic of latest time-to-break $T_{3}$.

which could shorten the time to judge side impacts and defuse the hazards of unacceptable behaviors of the battery system.

Table 2 shows the latest time-to-break for DC contactors to break electric loops and the response time range of identification algorithm against different collision velocity obtained by employing FEA. $T_{3}$ is the moment that the gap between the door frame and the rear panel reaches to the smallest distance. And the value of $T_{3}$ is about $20 \mathrm{~ms}-30 \mathrm{~ms}$, which obliges the collision identification algorithm to detect a collision signal within very short time. Apart from fast response, the collision identification algorithm should have high noise immunity.

Based on above study on the time-to-break for power battery pack, the response time of side impact identification algorithm is not more than $20 \mathrm{~ms}$. That is to say that the controller triggers a breaking signal before the gap between the door frame and the rear panel reaches to the minimum. First of all, we must make sure that the impact discrimination algorithm should respond as soon as possible. Secondly, the side impact identification algorithm should be sensitive enough to the collision strength. It means that the identification algorithm should trigger a breaking signal earlier in severe collision than in moderate collision. Thirdly, due to severe vibration from the pavement, the identification algorithm should exhibit robust performance and is able to trigger a breaking signal for power battery pack promptly.

According to the above detailed analysis, the combination of moving window algorithm (MWA) and improved moving window algorithm (IMWA) is selected as the side impact identification algorithm for electric buses. MWA is a method of the integral operation of the value of acceleration; IMWA changes its integral mathematic object $a(t)$ to $|a(t)|$.

\section{Side Impact Safety Control Strategy}

3.1. Some Principles for MWA. Figure 11 shows the change process of acceleration obtained by an acceleration sensor placed on the battery pack, $a(t)$. TIME denotes the beginning of side collision and the figure shows time window width 
TABLE 2: Latest time to break and algorithms response time.

\begin{tabular}{lccccc}
\hline Time/ms & \multicolumn{5}{c}{ Collision Velocity/km/h } \\
& 40.0 & 48 & 50.0 & 60.0 & 70.0 \\
\hline$T_{3}$ & 30.0 & 26 & 25.0 & 23.0 & 20.0 \\
$\Delta T_{1}$ & $<30-\Delta T_{2}$ & $<26-\Delta T_{2}$ & $<25-\Delta T_{2}$ & $<23-\Delta T_{2}$ & $<20-\Delta T_{2}$ \\
\hline
\end{tabular}

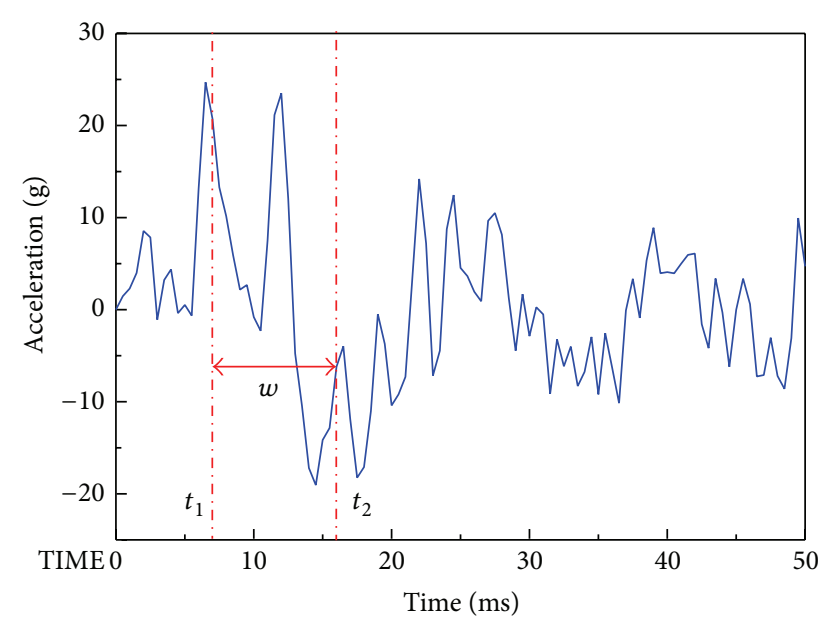

FIgure 11: Acceleration curve.

$\left[t_{1}, t_{2}\right]$; then variable $a(t)$ is integrated within the time window [19-24]:

$$
S\left(t_{1}, t_{2}\right)=\int_{t_{1}}^{t_{2}} a(t) d t
$$

Time window width $w$, namely, $w=t_{2}-t_{1}$.

With $w$ substituting the variable $t_{2}$, formula (3) can be reformulated as

$$
S(t, w)=\int_{t-w}^{t} a(t) d t .
$$

Actually, $a(t)$ is obtained at a fixed-sample frequency and is discrete. Formula (4) can be further rewritten into a discrete form:

$$
S(n, k)=\frac{1}{f} \sum_{i=n-k+1}^{n} a(i),
$$

where $n$ is the current time point, $k$ is the number of sampling points, and $f$ is the sampling frequency.

After analysis of the above formula, the velocity change $S(n, k)$ greatly differs in different window width. Then it is hard to evaluate the performance of breaking capacity against different window widths. In order to analyze sensitivity and antijamming capability against different window width $S(n, k)$ should be normalized. The normalized metric $G(n, k)$ is completed leaving $|S(n, k)|$ divided by the maximum $\left|S(n, k)_{\max }\right|:$

$$
G(n, k)=\frac{|S(n, k)|}{\left|S(n, k)_{\max }\right|} .
$$

Taking the real-time requirement into consideration, it is inappropriate for window width to select greater value of window width. Therefore, $w$ is selected at $2 \mathrm{~ms}, 4 \mathrm{~ms}$, and $6 \mathrm{~ms}$ when sample time is $1 \mathrm{~ms}$. Then, according to the above algorithm, the data from the same collision velocity are processed. As shown in Figure 12, the shape of the three curves has similar trend, but has a different sensitivity. If a threshold is selected at $R$, the three curves take different times to reach to the threshold $R$, and $t_{6}>t_{4}>t_{2}$, which means window width $6 \mathrm{~ms}$ could earlier identify a collision signal. So it is concluded that the slope of window width $6 \mathrm{~ms}$ is greater than others. The greater the slope of the curve is, the higher the sensitivity of the collision strength is. When $w$ is $2 \mathrm{~ms}$, the slope is smaller than the other two, meaning that the algorithm is not sensitive enough to detect the collision strength. Since the interval between battery door frame and the front panel of battery pack is only $25 \mathrm{~mm}$, the controller has to identify the collision strength rapidly, and trigger a breaking signal within $20 \mathrm{~ms}$. Therefore, the window width of $2 \mathrm{~ms}$ is discarded. In addition, the real-time performance of $6 \mathrm{~ms}$ will get worse. The reason is that the Algorithm runs 15 times with $6 \mathrm{~ms}$ window width and 17 times with $4 \mathrm{~ms}$. Through the above analysis, the selective window width of $4 \mathrm{~ms}$ is employed in this paper.

3.2. Performance of MWA. Figure 13 is a curve of moving window integration algorithm with window width $4 \mathrm{~ms}$ against different collision velocities, such as $20 \mathrm{~km} / \mathrm{h}$, $25 \mathrm{~km} / \mathrm{h}, 28 \mathrm{~km} / \mathrm{h}$, and $30 \mathrm{~km} / \mathrm{h}$. In analysis of the curve, a peak value can reach 0.47 at $20 \mathrm{~km} / \mathrm{h}$. What is more, with increasing collision velocity, the peak will arrive in advance. For example, a peak value can reach 0.69 at $25 \mathrm{~km} / \mathrm{h}$. Through the above analysis of $\Delta T_{1}, 0.5$ is selected as a threshold of collision recognition algorithm, namely, time-to-integral. The controller starts the recognition algorithm.

3.3. Performance of IMWA. On high-speed collisions, the collision energy is absorbed by the body frame and the battery pack system within a very short time. This condition, combined with high intrusion velocities, results in a short time between the beginning of the collision and the moment when the intruding door panel contacts the power battery. It is very significant for identification algorithm to detect the collision strength rapidly, and then it is necessary to improve the response time of the identification algorithm. Therefore, an improved moving window algorithm is discussed fundamentally, and the integral operation of the absolute value of acceleration is selected as an optimal method. Because of IMWA changing the integral mathematic object $a(t)$ to $|a(t)|$, its slope becomes elevated with window width $4 \mathrm{~ms}$. 


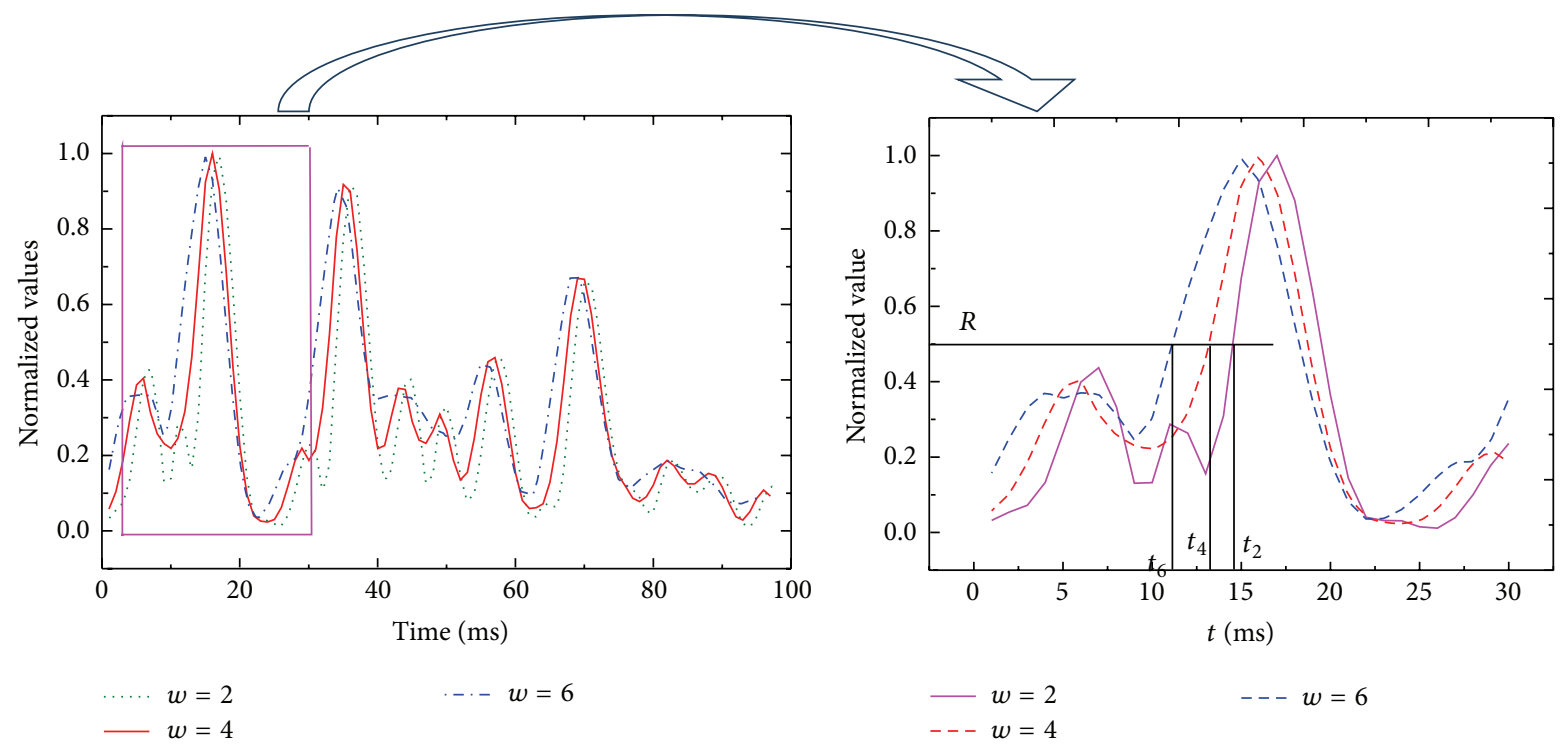

FIGURE 12: Normalization function $G(n, k)$.

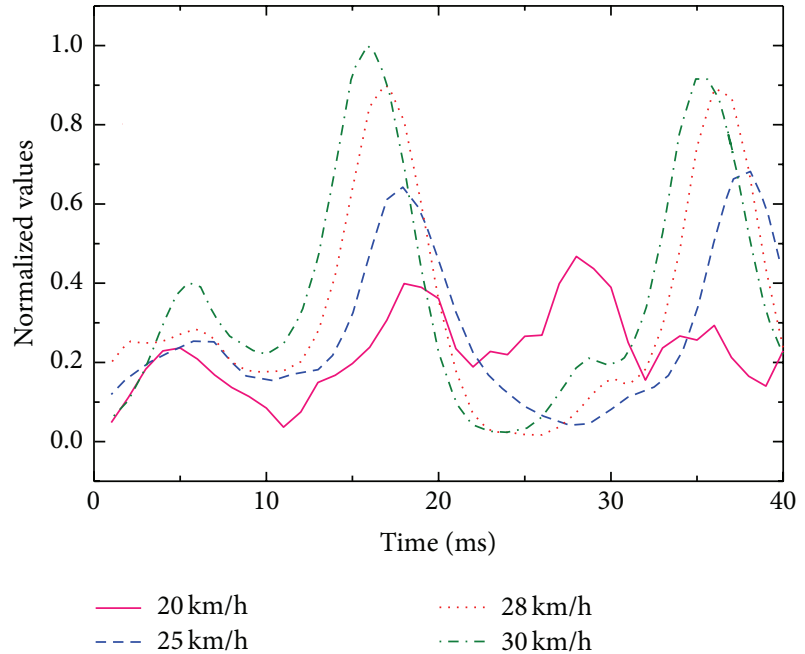

FIGURE 13: Integration value against different collision velocity.

Figure 14 shows a curve of moving window integration algorithm and improved moving window integration algorithm with window width $4 \mathrm{~ms}$ at $40 \mathrm{~km} / \mathrm{h}$, where $A T$ is a threshold. $A T_{1}$ is the moment to make the DC contactor breaking electric loops based on improved moving window algorithm, $A T_{2}$ is the moment to make the DC contactor breaking electric loops based on moving window algorithm. Obviously $A T_{2}>A T_{1}$. Accordingly, it could be concluded that MWA is not component to detect fierce collision strength in advance and IMWA is enough sensitive to detect the collision strength in advance. Although the improvement is not conspicuous, it is significant to detect side impact as soon as possible.

Figure 15 shows a graph of $\int|a(t)| d t$ at $45 \mathrm{~km} / \mathrm{h}$ as well as a graph of $\int a(t) d t$ at $25 \mathrm{~km} / \mathrm{h}, 45 \mathrm{~km} / \mathrm{h}$, respectively. Where

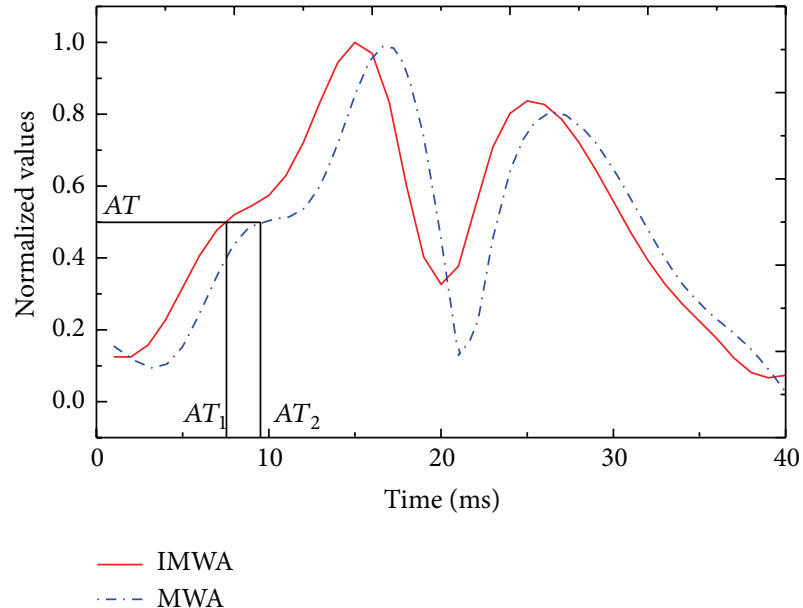

Figure 14: Contrast between IMWA and MWA.

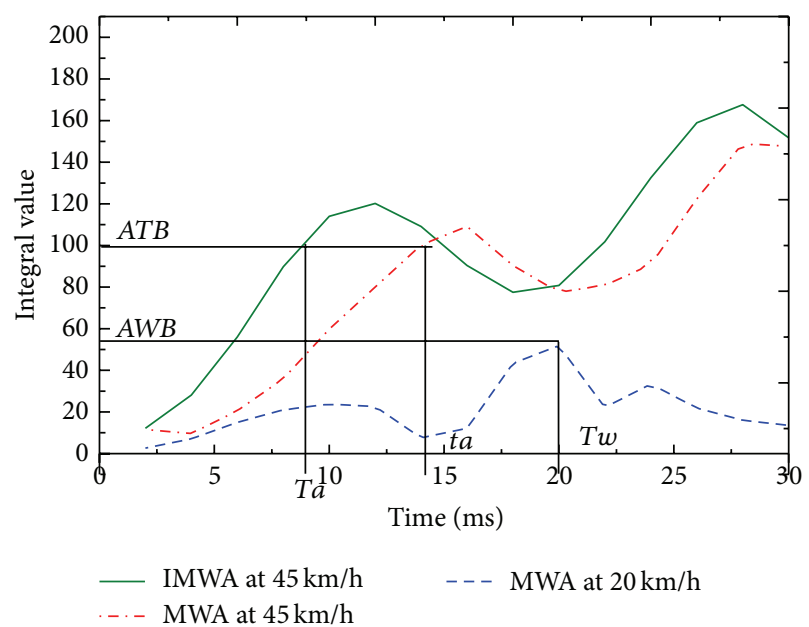

FIGURE 15: Recognition for collision severity. 


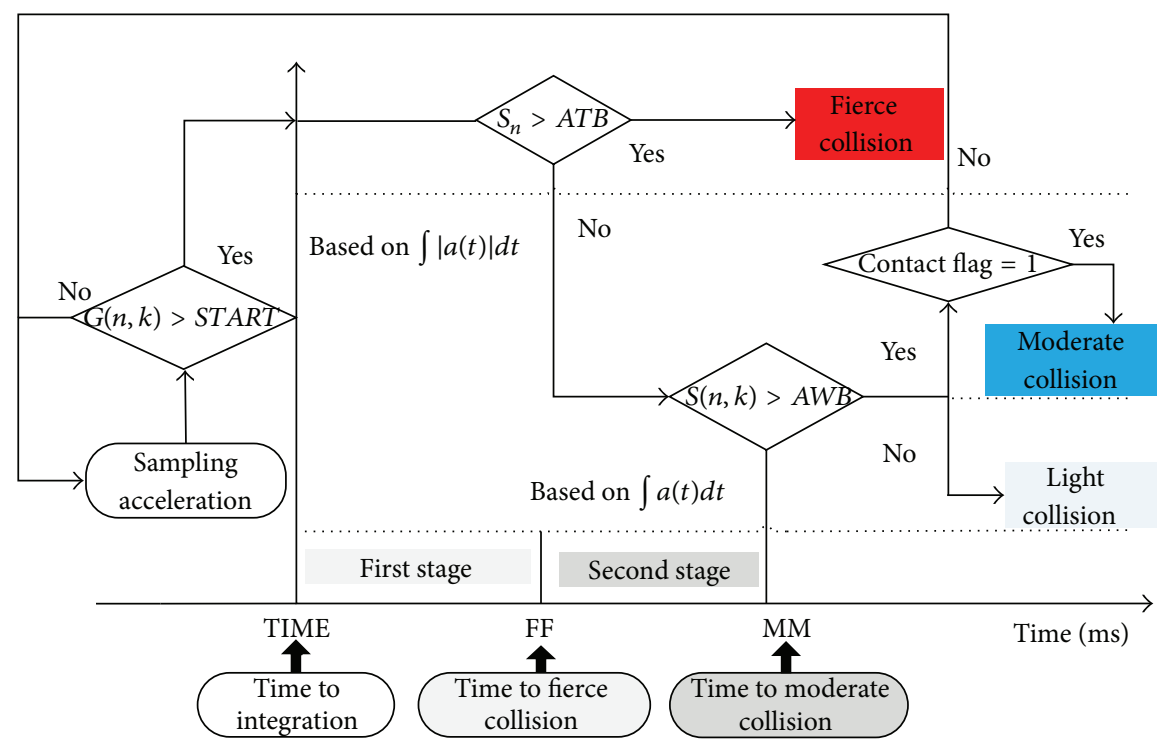

FIGURE 16: Schematic of breaking control algorithm.

$A T B$ and $A W B$ are two different thresholds which classify collision strength into three levels including light collision, moderate collision, and fierce collision. $\mathrm{Ta}$ is the moment to make the DC contactor breaking electric loops at $45 \mathrm{~km} / \mathrm{h}$; $T w$ is the moment to make the DC contactor breaking electric loops at $25 \mathrm{~km} / \mathrm{h}$. Collision strength can be described as

$$
\begin{gathered}
\text { Severity }=\left\{\begin{array}{l}
\text { Light Collision (LC) } \\
\text { Modearte Collision }(\mathrm{MC}), \\
\text { Fierce Collision }(\mathrm{FC}),
\end{array}\right. \\
\mathrm{LC} \longrightarrow S_{t_{1} / f}<A W B, \\
\mathrm{MC} \longrightarrow S_{t_{1} / f}>A W B, S_{t_{2} / f}<A T B, \\
\mathrm{FC} \longrightarrow S_{t_{2} / f}>A T B,
\end{gathered}
$$

where $t_{1} / f$ and $t_{2} / f$ are discrete-time corresponding to $t_{1}$ and $t_{2}$, respectively.

\subsection{Specific Implementation of Side Impact Safety Control} Strategy. Based on the above analysis of the two algorithms, this paper proposes a novel algorithm for detecting collision strength, including two parameters of $S_{n}$ based on the integration for the absolute value of acceleration, $\int|a(t)| d t$, and $S(n, k)$ based on the moving window integration, $\int a(t) d t$. Figure 16 shows a schematic diagram of the algorithm. Twostage identification method to detect the collision strength is employed. START is a threshold; if $G(n, k)>$ START, the controller will start impact identify algorithm. TIME is a symbol, time to integration.

The details are described as follows.

(a) Real-time detection is for the impact acceleration signal. (b) If $G(n, k)>$ START, TIME is the moment to conduct integrating computation; then skip to step (c), else return (a).

(c) If $S_{n}>A T B$, it means that fierce collision occurs and the breaking signal is triggered simultaneously; else skip to step (d).

(d) If $S(n, k)>A W B$, it means that moderate collision occurs and further judgments are required. The contact impact sensors make a determination whether or not the collision occurs. If does, a breaking signal is triggered simultaneously.

(e) If $S(n, k)<A W B$, it means that light collision occurs and it not necessary to trigger a breaking signal.

\section{Selection of Important Parameters}

4.1. Determination for Threshold AWB. A battery management system, insurance, and other electrical components are arranged between the front panel and the rear panel of the battery pack. The damaged condition of electrical component is closely relevant to the relative deformation of the panel. Since the door frame of the battery pack is closed to the body frame, the door frame could absorb more energy than the front panel of battery pack. Considering energy absorption ratio, a weight parameter $\lambda(\lambda=0.7)$ is introduced. An equivalent expression of intrusion rate is defined as $\eta$ :

$$
\eta=\frac{(1-\lambda) \delta_{2}+\lambda \delta_{1}}{\delta}
$$

where $\delta_{1}$ is the relative intrusion volume between the door frame of the battery pack and the front panel of the battery pack, $\delta_{2}$ is the relative intrusion volume between the rear panel and the front panel of the battery pack, $\delta$ is the equivalent interval between the door frame of the battery pack and the rear panel of the battery pack, and $\delta=42 \mathrm{~mm}$ 

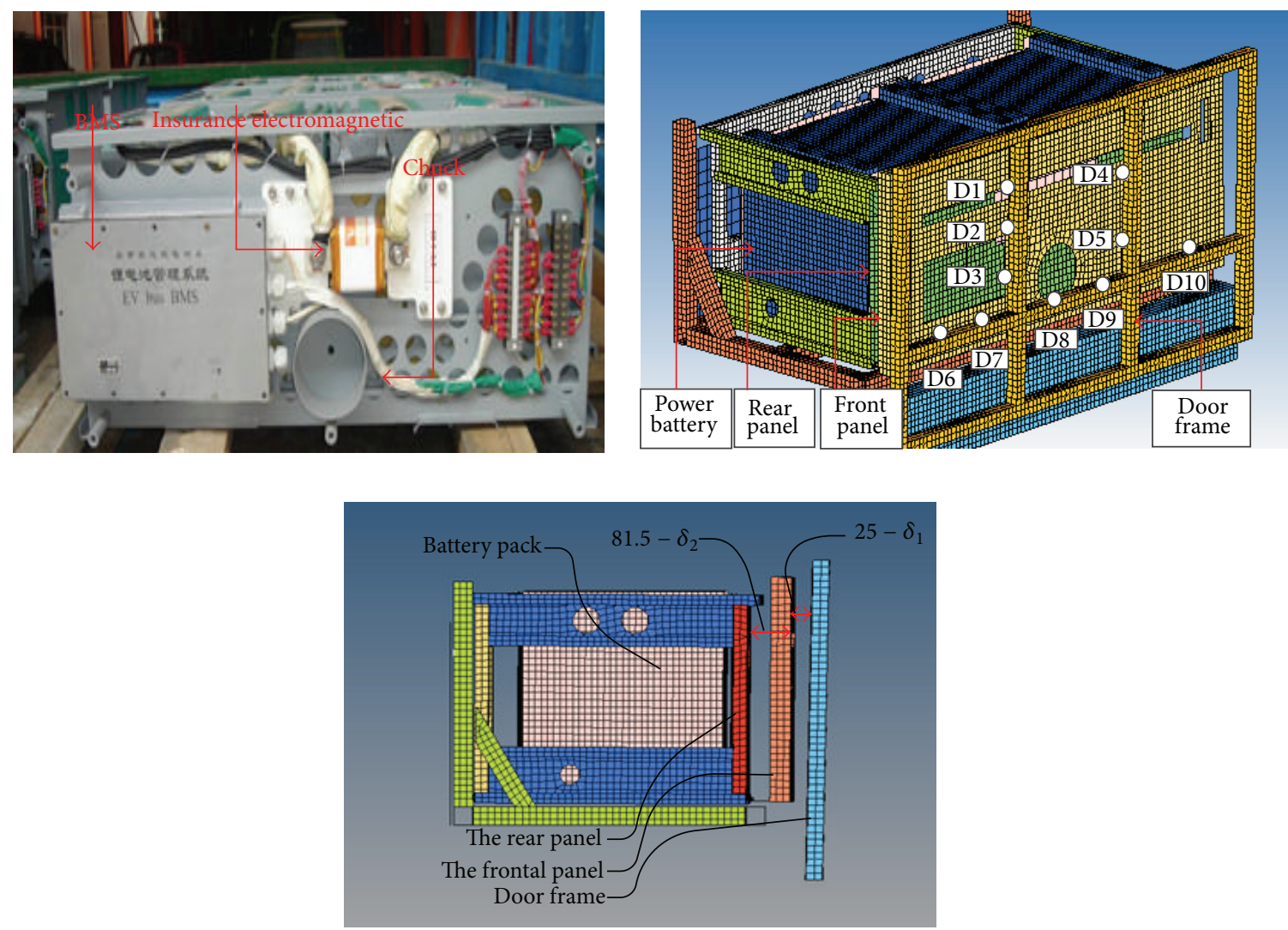

FIGURE 17: Battery pack and test points.

$(42=81.7 \times 0.3+25 \times 0.7)$. The initial gap between the rear panel and the front panel of the battery pack is $81.7 \mathrm{~mm}$. The initial gap between the door frame of the battery pack and the front panel of the battery pack is $25 \mathrm{~mm}$.

The parameter $\eta$ is employed as a metric to indicate the damage degree to the battery pack. Figure 17 shows the selected ten different points on the door frame as measure points, recording displacement of each point. Then these ten points project to the rear panel and the front panel of the battery pack, respectively, recording the displacement of projection points. Table 3 shows intrusion volume and intrusion rate of measure points at $20 \mathrm{~km} / \mathrm{h}$ and $25 \mathrm{~km} / \mathrm{h}$.

Table 3 shows that the average invasion rate is $23 \%$ approximately, and the average of $\delta_{1}$ is $14 \mathrm{~mm}$. Nevertheless, the initial gap between the door frame of the battery pack and the front panel of the battery pack is $25 \mathrm{~mm}$. Obviously, both of them are not contact each other. The average of $\delta_{2}$ is $3 \mathrm{~mm}$. Taking into account the gap between the battery box, insurance and other electrical components, and the front panel of battery pack, the intrusion volume does not harm these important electrical components. Although $\delta_{1}$ increases insignificantly and $\eta$ is no more than $5 \%$, the average of $\delta_{2}$ is $5 \sim 6 \mathrm{~mm}$ and the intrusion volume of one measure point reaches $8 \mathrm{~mm}$ at $25 \mathrm{~km} / \mathrm{h}$. Taking the narrow gap into consideration, the peak integration of collision acceleration at $25 \mathrm{~km} / \mathrm{h}$ is defined as a metric distinguishing moderate collision from light collision.
Employing moving window integration $(w=4 \mathrm{~ms})$ for acceleration signal at $25 \mathrm{~km} / \mathrm{h}$, a maximum value is obtained, namely,

$$
A W B=\frac{1}{f} \sum_{i=0}^{n} a(i)
$$

where $a(i)$ is discrete acceleration signal and $f$ is the sampling frequency. Figure 18 is the schematic diagram of the threshold $A W B$.

4.2. Determination for Threshold ATB. Table 4 shows that $\delta_{1}$ becomes less than the value at the low-speed collision. By detailed analysis, it is due to enormous plastic deformation for the door frame of the battery pack that results in plastic deformation invalidation of partial door frame. And then energy absorbed by the door frame dramatically decreases, while energy absorbed by the front panel dramatically increases. At $45 \mathrm{~km} / \mathrm{h}$ and $50 \mathrm{~km} / \mathrm{h}, \delta_{2}$ reach $23.5 \mathrm{~mm}$ and $25.2 \mathrm{~mm}$, respectively. It means that this severely endangers battery management systems, insurance, and other important electrical components. Furthermore, FEA results show that nondestructive plastic deformation for door frame occurs at $40 \mathrm{~km} / \mathrm{h}$. Therefore, the integration of absolute acceleration at $45 \mathrm{~km} / \mathrm{h}$ is defined as a metric distinguishing fierce collision from moderate collision. 
TABLE 3: Intrusion volume, rate of invasive at low-speed collision.

\begin{tabular}{|c|c|c|c|c|c|c|c|c|c|c|c|}
\hline \multicolumn{2}{|c|}{$\begin{array}{c}\text { Test Points } \\
\text { Collision Velocity } \\
\mathrm{km} / \mathrm{h}\end{array}$} & \multirow{2}{*}{$\begin{array}{c}\mathrm{D} 1 \\
14.0\end{array}$} & \multirow{2}{*}{$\begin{array}{r}\mathrm{D} 2 \\
13.3\end{array}$} & \multirow{2}{*}{$\begin{array}{c}\text { D3 } \\
14.2\end{array}$} & \multirow{2}{*}{$\begin{array}{c}\mathrm{D} 4 \\
13.3\end{array}$} & \multirow{2}{*}{$\begin{array}{l}\text { D5 } \\
13.1\end{array}$} & \multirow{2}{*}{$\begin{array}{c}\text { D6 } \\
12.5\end{array}$} & \multirow{2}{*}{$\begin{array}{r}\text { D7 } \\
14.3\end{array}$} & \multirow{2}{*}{$\begin{array}{c}\text { D8 } \\
14.8\end{array}$} & \multirow{2}{*}{$\begin{array}{c}\text { D9 } \\
16.0\end{array}$} & \multirow{2}{*}{$\begin{array}{l}\text { D10 } \\
13.9\end{array}$} \\
\hline & $\delta_{1} / \mathrm{mm}$ & & & & & & & & & & \\
\hline \multirow[t]{2}{*}{20} & $\delta_{2} / \mathrm{mm}$ & 2.0 & 3.7 & 3.8 & 3.6 & 5.0 & 1.0 & 2.8 & 4.7 & 3.2 & 0.7 \\
\hline & $\eta / \%$ & 22.5 & 22.7 & 24.2 & 22.7 & 23.4 & 19.5 & 23.6 & 25.7 & 26.4 & 21.4 \\
\hline \multirow{3}{*}{25} & $\delta_{1} / \mathrm{mm}$ & 13.6 & 14.5 & 15.1 & 18.8 & 11.4 & 12.5 & 14.0 & 14.3 & 14.9 & 14.9 \\
\hline & $\delta_{2} / \mathrm{mm}$ & 4.5 & 4.4 & 4.7 & 5.3 & 7.9 & 3.2 & 3.8 & 6.5 & 6.9 & 3.7 \\
\hline & $\eta / \%$ & 23.8 & 25.1 & 26.2 & 32.2 & 23.0 & 21.1 & 23.9 & 26.3 & 27.5 & 25.4 \\
\hline
\end{tabular}

TABLE 4: The intrusion volume, the rate of invasive a thigh-speed collision.

\begin{tabular}{|c|c|c|c|c|c|c|c|c|c|c|c|}
\hline \multicolumn{2}{|c|}{$\begin{array}{c}\text { Test Points } \\
\text { Collision Velocity } \\
\mathrm{km} / \mathrm{h}\end{array}$} & \multirow{2}{*}{$\begin{array}{c}\text { D1 } \\
-0.4\end{array}$} & \multirow{2}{*}{$\begin{array}{l}\mathrm{D} 2 \\
1.57\end{array}$} & \multirow{2}{*}{$\begin{array}{c}\mathrm{D} 3 \\
7.9\end{array}$} & \multirow{2}{*}{$\begin{array}{l}\mathrm{D} 4 \\
4.5\end{array}$} & \multirow{2}{*}{$\begin{array}{l}\text { D5 } \\
6.15\end{array}$} & \multirow{2}{*}{$\begin{array}{l}\text { D6 } \\
7.3\end{array}$} & \multirow{2}{*}{$\begin{array}{l}\text { D7 } \\
6.3\end{array}$} & \multirow{2}{*}{$\begin{array}{r}\text { D8 } \\
8.9\end{array}$} & \multirow{2}{*}{$\begin{array}{l}\text { D9 } \\
13.1\end{array}$} & \multirow{2}{*}{$\begin{array}{r}\mathrm{D} 10 \\
11.5\end{array}$} \\
\hline & $\delta_{1} / \mathrm{mm}$ & & & & & & & & & & \\
\hline \multirow[t]{3}{*}{45} & $\delta_{2} / \mathrm{mm}$ & 29 & 30 & 25.4 & 21.2 & 23.7 & 25.3 & 23.3 & 23.6 & 21.2 & 12.6 \\
\hline & $\eta / \%$ & - & - & - & - & - & - & - & - & - & - \\
\hline & $\delta_{1} / \mathrm{mm}$ & -4.6 & 0 & 7.3 & 1.2 & 4.5 & 10.6 & 11 & 6.5 & 13.0 & 11.9 \\
\hline \multirow[t]{2}{*}{50} & $\delta_{2} / \mathrm{mm}$ & 30.5 & 32.9 & 29.2 & 22.9 & 25.0 & 27.9 & 16.4 & 27.5 & 24.0 & 15.5 \\
\hline & $\eta / \%$ & - & - & - & - & - & - & - & - & - & - \\
\hline
\end{tabular}

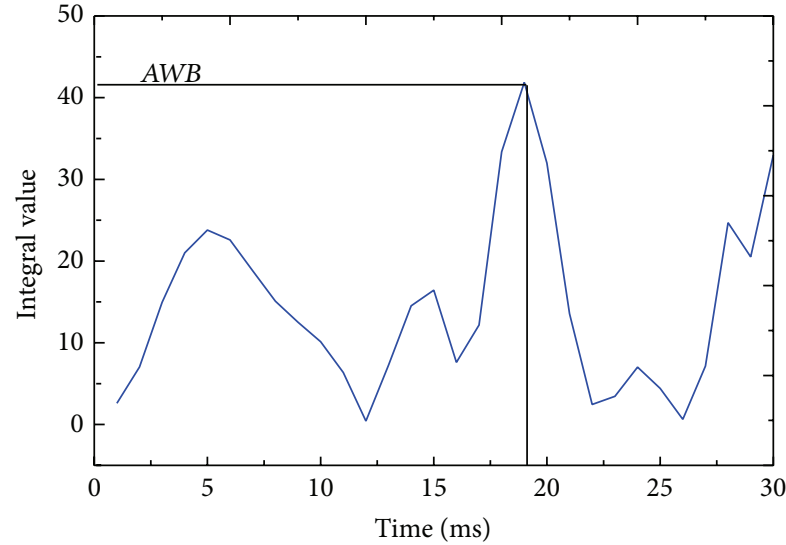

MWA at $20 \mathrm{~km} / \mathrm{h}$

FIgURE 18: Schematic of threshold $A W B$.

Employing improved moving window integration $(w=$ $4 \mathrm{~ms}$ ) for acceleration signal at $45 \mathrm{~km} / \mathrm{h}$, a maximum value is obtained, namely,

$$
A T B=\frac{1}{f} \sum_{i=0}^{n}|a(i)|,
$$

where $a(i)$ is discrete acceleration signal and $f$ is the sampling frequency. Figure 15 is a schematic diagram of the threshold $A T B$. Obviously $t a>T a$. The figure shows that the controller triggers a break signal based on IWMA sooner than that based on WMA in serious impacts. So it is concluded that the IMWA is component to detect the high-speed collision strength in advance.

\section{Reliability Analysis of Impact Safety Control Strategy}

Table 5 shows side impact simulation experiment results. Taking advantage of Hyperworks and Ls-dyna, simulation data is obtained, evaluating the performance for moving window integral algorithm and side impact discrimination algorithm. It is concluded that breaking control algorithm is superior to moving window integral algorithm.

\section{Conclusion}

In order to enhance the overall safety performance of electric vehicles in side impacts, this paper presents a side impact safety control strategy for an example electric bus, aiming at defusing the hazards of unacceptable behaviors of the battery system such as high-voltage hazards. Based on the collision detection metrics, that is, velocity change and integral for absolute acceleration, a side impact discrimination algorithm and a side impact severity algorithm have been developed to identify the impact signal as well as to assess the extent of the accident. If a collision signal is identified according to those algorithms, the controller triggers a breaking signal making the DC contactors break the electrical loops promptly, which are duly placed between adjacent modules. This can significantly reduce the voltage level of the battery pack, thus effectively suppressing the hazards on account of the possible terminal exposure to the passengers. In addition, the reliability of the side impact safety control strategy (side impact discrimination algorithm) developed in this paper is evaluated for other acceleration signals generated 
TABLE 5: Impact simulation tests.

\begin{tabular}{|c|c|c|c|c|}
\hline \multicolumn{5}{|c|}{ Actual Time to Break (ms) } \\
\hline & & MWA & $\begin{array}{c}\text { Side Impact Discrimination } \\
\text { Algorithm }\end{array}$ & Aimed Time to Break (ms) \\
\hline \multirow{5}{*}{$\mathrm{LC}$} & $20.0 \mathrm{~km} / \mathrm{h}$ & NB & NB & NB \\
\hline & $23.0 \mathrm{~km} / \mathrm{h}$ & NB & NB & NB \\
\hline & $25.0 \mathrm{~km} / \mathrm{h}$ & NB & NB & NB \\
\hline & $23.0 \mathrm{~km} / \mathrm{h}$ (unfiltered) & NB & NB & NB \\
\hline & $25.0 \mathrm{~km} / \mathrm{h}$ (unfiltered) & $\mathrm{B}$ & NB & NB \\
\hline \multirow{5}{*}{ MC } & $28.0 \mathrm{~km} / \mathrm{h}$ & 23 & 23 & $<37-\Delta T_{2}$ \\
\hline & $30.0 \mathrm{~km} / \mathrm{h}$ & 20.0 & 20.0 & $<33-\Delta T_{2}$ \\
\hline & $40.0 \mathrm{~km} / \mathrm{h}$ & 15.0 & 15.0 & $<30-\Delta T_{2}$ \\
\hline & $43.0 \mathrm{~km} / \mathrm{h}$ & 14.0 & 14.0 & $<30-\Delta T_{2}$ \\
\hline & $30.0 \mathrm{~km} / \mathrm{h}$ (unfiltered) & 25.0 & 24.0 & $<33-\Delta T_{2}$ \\
\hline \multirow{5}{*}{ FC } & $48.0 \mathrm{~km} / \mathrm{h}$ & 13.0 & 11.5 & $<26-\Delta T_{2}$ \\
\hline & $50.0 \mathrm{~km} / \mathrm{h}$ & 12.0 & 10.0 & $<25-\Delta T_{2}$ \\
\hline & $52.0 \mathrm{~km} / \mathrm{h}$ & 12.0 & 9.0 & $<24.5-\Delta T_{2}$ \\
\hline & $60 \mathrm{~km} / \mathrm{h}$ & 11 & 8 & $<23-\Delta T_{2}$ \\
\hline & $48.0 \mathrm{~km} / \mathrm{h}$ (unfiltered) & 15.0 & 13.5 & $<26-\Delta T_{2}$ \\
\hline
\end{tabular}

"NB" means "not trigger a breaking signal". "B" means "trigger a breaking signal".

by simulation. The results verify that the side impact safety control strategy can trigger the breaking signal in promptly.

\section{Disclosure}

The paper has not been previously published or currently submitted for the review of any other journal and will not be submitted elsewhere before a decision is made by this journal. Its publication is approved by all authors and explicitly by the responsible authorities where the work was carried out.

\section{Conflict of Interests}

Zhen-po Wang, Jia Liu, Lei Zhang, and Hai-tao Li declare that there is no conflict of interests regarding the publication of this paper.

\section{References}

[1] B. Scrosati, J. Hassoun, and Y. K. Sun, "Lithium-ion batteries. A look into the future," Energy \& Environmental Science, vol. 4, no. 9, pp. 3287-3295, 2011.

[2] L. Zhang, Z. Wang, F. Sun, and D. G. Dorrell, "Online parameter identification of ultracapacitor models using the extended Kalman filter," Energies, vol. 7, no. 5, pp. 3204-3217, 2014.

[3] L. Zhang, Z. Wang, X. Hu, F. Sun, and D. G. Dorrell, "A comparative study of equivalent circuit models of ultracapacitors for electric vehicles," Journal of Power Sources, vol. 274, pp. 899906, 2015.

[4] J. Kim, J. Lee, and E. Kim, "Technical feasibility study on avoidance or mitigation of side collisions at intersections," SAE Technical Paper 2012-01-0090, SAE International, 2012.

[5] N. J. Luzon, D. C. Arregui, and L. M. Hernando, "Innovative passive and active countermeasures for near side crash safety,"
International Journal of Crashworthiness, vol. 19, no. 3, pp. 209221, 2013.

[6] Y. Aoki, H. S. Kim, and G. Ben, "Impact strength and response behaviour of CFRP guarder belt for side collision of automobiles," International Journal of Crashworthiness, vol. 14, no. 5, pp. 469-476, 2009.

[7] Y. Chen, Z. Tang, X. Lu, and C. Tan, "Research of explosion mechanism of lithium-ion battery," Progress in Chemistry, vol. 18, no. 6, pp. 823-831, 2006.

[8] D. Lisbona and T. Snee, "A review of hazards associated with primary lithium and lithium-ion batteries," Process Safety and Environmental Protection, vol. 89, no. 6, pp. 434-442, 2011.

[9] P. Ribière, S. Grugeon, M. Morcrette, S. Boyanov, S. Laruelle, and G. Marlair, "Investigation on the fire-induced hazards of Liion battery cells by fire calorimetry," Energy \& Environmental Science, vol. 5, no. 1, pp. 5271-5280, 2012.

[10] H. Yang, S. Amiruddin, and H. J. Bang, "A review of Li-ion cell chemistries and their potential use in hybrid electric vehicles," Journal of Industrial and Engineering Chemistry, vol. 12, no. 1, pp. 12-38, 2006.

[11] Q. Wang, P. Ping, X. Zhao, G. Chu, J. Sun, and C. Chen, “Thermal runaway caused fire and explosion of lithium ion battery," Journal of Power Sources, vol. 208, pp. 210-224, 2012.

[12] P. G. Balakrishnan, R. Ramesh, and T. Prem Kumar, "Safety mechanisms in lithium-ion batteries," Journal of Power Sources, vol. 15, no. 2, pp. 401-414, 2006.

[13] W. Sinz, C. Breitfuß, E. Tomasch et al., "Integration of a crashworthy battery in a fully electric city bus," International Journal of Crashworthiness, vol. 17, no. 1, pp. 105-118, 2012.

[14] J. S. Lee, J. Kim, K. H. Nam, H. Bae, J. T. Sung, and W. Nah, "EM analysis of high voltage connector for hybrid/electric vehicle," Transactions of the Korean Institute of Electrical Engineers, vol. 60, no. 1, pp. 131-137, 2011.

[15] J. X. Zhu, R. L. Zheng, and B. Zhuo, "A research on the diagnosis and control strategy for high voltage safety of electric vehicle," 
The Journal of Automobile Engineering, vol. 29, no. 4, pp. 308312, 2007.

[16] J. K. Lee, J. S. Yeo, M. C. Jang, J. M. Yoon, and D. M. Kang,"Mechanical durability and electrical durability of an aluminium-laminated lithium-ion polymer battery pack for a hybrid electric vehicle," Proceedings of the Institution of Mechanical Engineers, Part D: Journal of Automobile Engineering, vol. 224, no. 6, pp. 765-773, 2010.

[17] W. K. Hang, S. D. Wan, and T. J. Zang, "Design and assessment of the high voltage of fuel cell in crash," Journal of Automobile Engineering, pp. 491-495, 2012.

[18] L.-B. Cao, J. Tong, Q. Deng, L.-M. Zhu, Y.-M. Tang, and Z.-H. Bai, "Study on the safety performance of HEB on high voltage," Journal of Hunan University Natural Sciences, vol. 35, no. 4, pp. 42-46, 2008.

[19] W. Q. Yin, Y. L. Wang, and P. P. Xu, "Review of ignition algorithms of vehicle airbag," Chinese Journal of Automotive Engineering, vol. 3, no. 2, pp. 79-87, 2013.

[20] M. A. Hannan, A. Hussain, and S. A. Samad, "Sensing systems and algorithms for airbag deployment decision," IEEE Sensors Journal, vol. 11, no. 4, pp. 888-890, 2011.

[21] T.-W. Park, H.-Y. Jeong, and S.-W. Park, "A crash severity algorithm for all frontal crash modes using compensation factors," Proceedings of the Institution of Mechanical Engineers, Part D, vol. 220, no. 5, pp. 531-541, 2006.

[22] H. R. Champion, J. Augenstein, and A. J. Blatt, "Automatic crash notification and the urgency algorithm: its history, value, and use," Advanced Emergency Nursing Journal, vol. 26, no. 2, pp. 143-156, 2004.

[23] M. A. Hannan, A. Hussain, A. Mohamed, and S. A. Samad, "Development of an embedded vehicle safety system for frontal crash detection," International Journal of Crashworthiness, vol. 13, no. 5, pp. 579-587, 2008.

[24] R. Ge, W. Zhu, and L. Zang, "A study on the control strategy for vehicle impact identification based on improved moving window algorithm," Journal of Automobile Engineering, vol. 33, no. 7, pp. 590-622, 2011.

[25] Z. H. Bai, P. P. Xu, Y. L. Wang, and X. G. Zhou, "Development of vehicle airbag ignition algorithm based on power-rate method," Advanced Materials Research, vol. 542-543, pp. 785-788, 2012.

[26] C. H. Lin, "Modeling and simulation of van for side impact sensing tests," in Proceedings of the 20th Enhanced Safety Vehicles Conference, Lyon, France, June 2007.

[27] C. Lin, Y. S. Wang, and X. F. Meng, "Chassis and vehicle body system," in Olympic Pure Electric Bus Technology and Applications, pp. 14-16, Institute of Technology Press, Beijing, China, 1st edition, 2008.

[28] T. Wierzbicki and W. Abramowicz, "On the crushing mechanics of thin-walled structures," Transactions ASME-Journal of Applied Mechanics, vol. 50, no. 4, pp. 727-734, 1983.

[29] Y. M. Hu, X. H. Li, and Z. X. Deng, "Numerical analysis technigues research for minicar front crash," JournaI of Chongging University: Natural Science Edition, vol. 26, no. 9, pp. 64-68, 2003. 


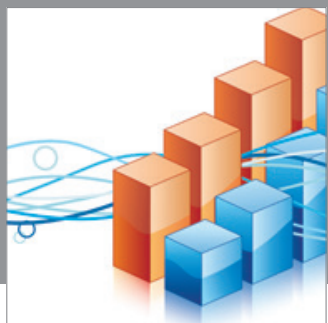

Advances in

Operations Research

mansans

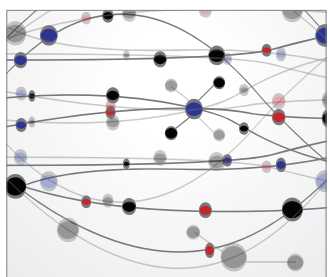

The Scientific World Journal
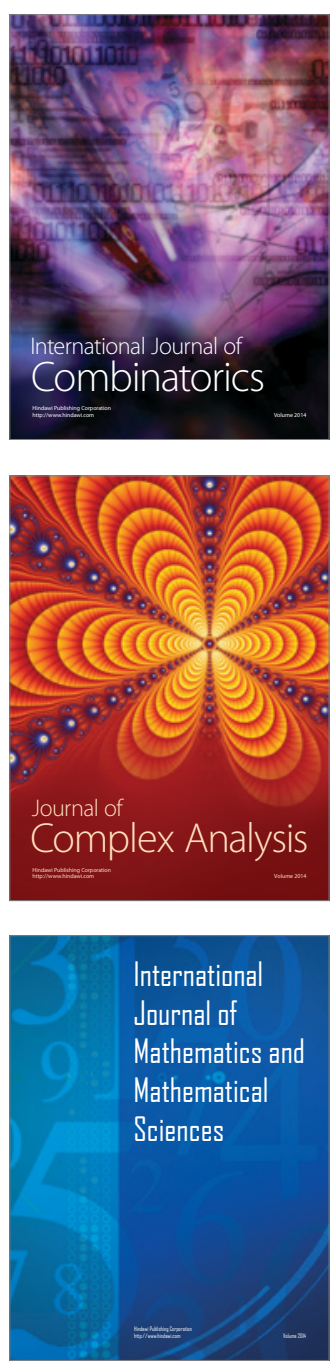
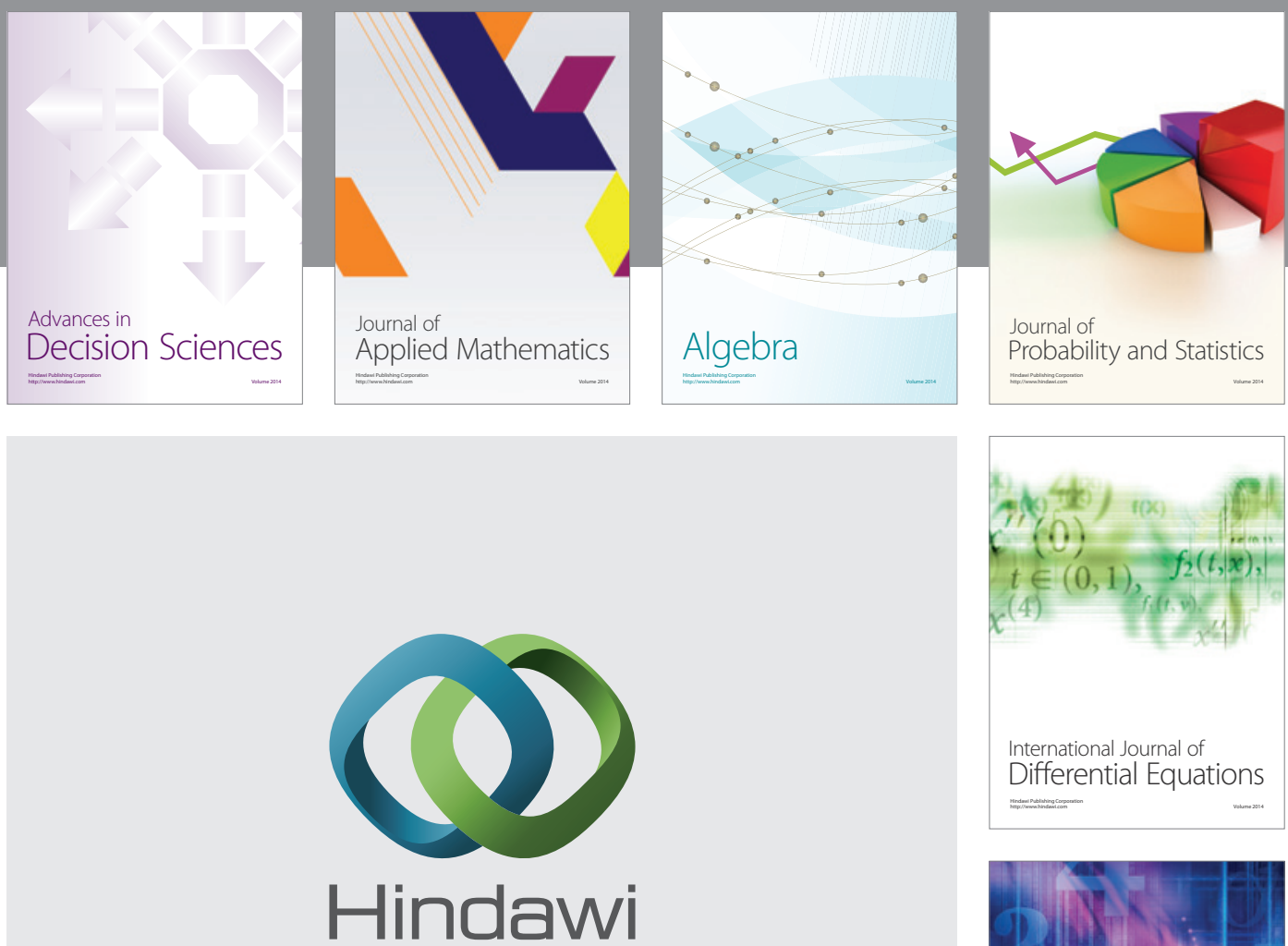

Submit your manuscripts at http://www.hindawi.com
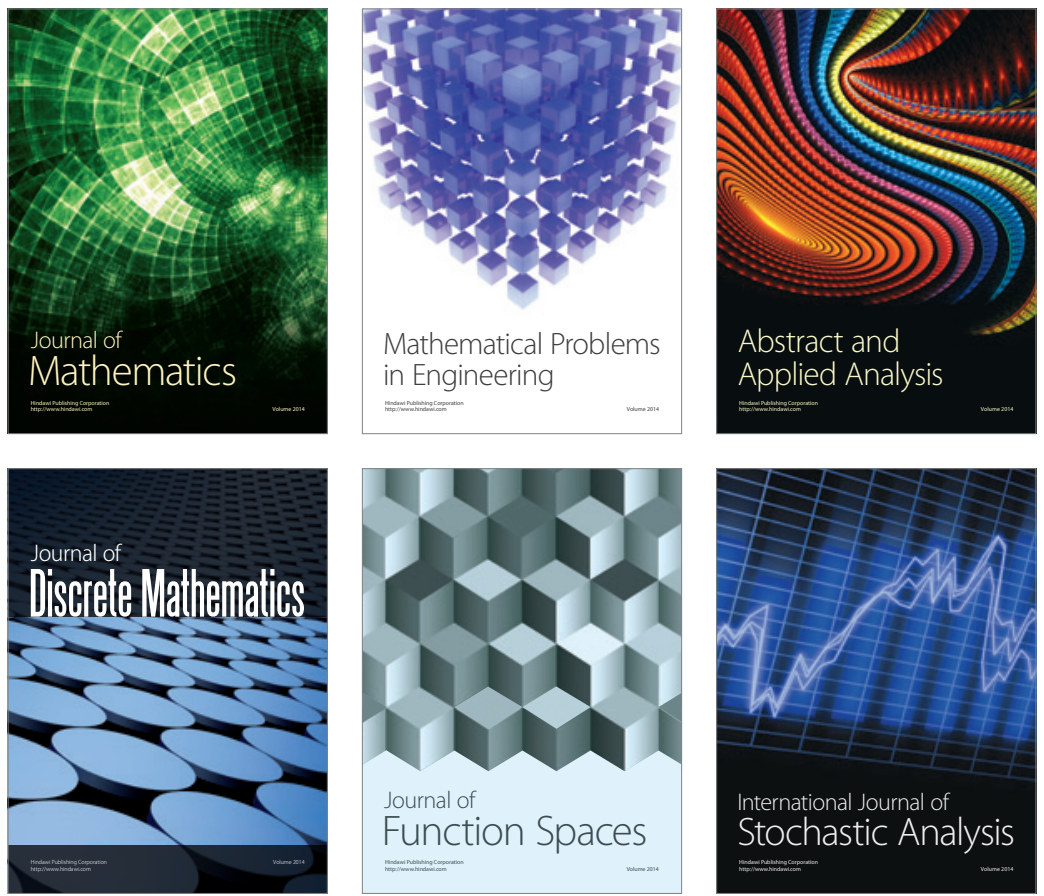

Journal of

Function Spaces

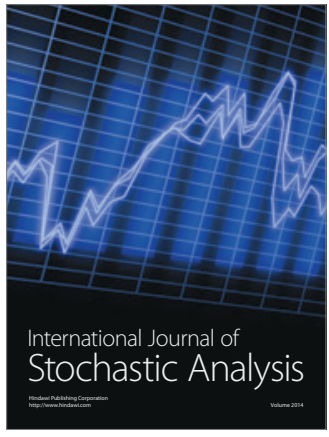

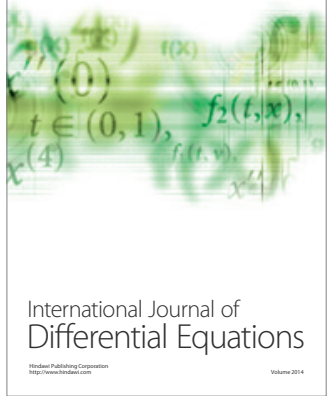
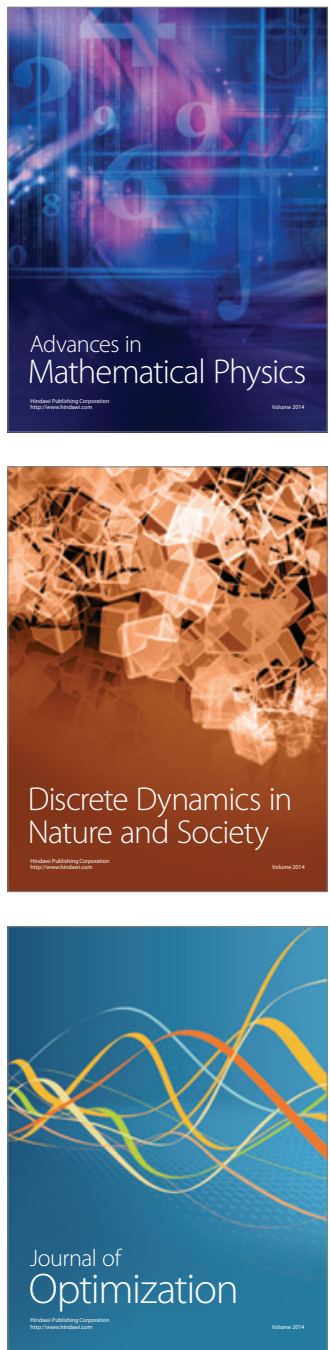